\title{
Effect of rotary systems and root canal preparation and dentin crack formation
}

\author{
Abdulkader Abdulelah Abulhamayel ${ }^{1 *}$, Hamdi Abdullah Altukhays ${ }^{2}$, Hatim Abdullah Alamri ${ }^{3}$, \\ Abdulrahman Ahmad Salem ${ }^{4}$, Jummar Ammar Farrash ${ }^{5}$, Adulelah Zaid Alshammari ${ }^{6}$, Rawan \\ Ibrahim Alhazmy ${ }^{7}$, Asmaa Ahmed Alghamdi ${ }^{7}$, Osama Sulaiman Alrasheed ${ }^{6}$, Mona Dabshi \\ Alanazi $^{8}$, May Mansour Alotaibi ${ }^{9}$
}

\author{
${ }^{1}$ Department of Endodontics, Khulais General Hospital, Khulais, Saudi Arabia \\ ${ }^{2}$ Department of Endodontics, Ad Dawadmi General Hospital, Dawadimi, Saudi Arabia \\ ${ }^{3}$ Department of Dental, King Fahad Armed Forcer Hospital, Jeddah, Saudi Arabia \\ ${ }^{4}$ General Dentist, Ministry of Health, Mecca, Saudi Arabia \\ ${ }^{5}$ General Dentist, Ministry of Health, Alwajh, Saudi Arabia \\ ${ }^{6}$ College of Dentistry, Al-Jouf University, Sakaka, Saudi Arabia \\ ${ }^{7}$ College of Dentistry, Umm Al-Qura University, Mecca, Saudi Arabia \\ ${ }^{8}$ Dental Department, Alsalam Hospital, Riyadh, Saudi Arabia \\ ${ }^{9}$ Dental Medical Complex in West of Riyadh, Ministry of Health, Riyadh, Saudi Arabia
}

Received: 01 October 2021

Accepted: 16 October 2021

*Correspondence:

Dr. Abdulkader Abdulelah Abulhamayel,

E-mail: abdulkader77@gmail.com

Copyright: () the author(s), publisher and licensee Medip Academy. This is an open-access article distributed under the terms of the Creative Commons Attribution Non-Commercial License, which permits unrestricted non-commercial use, distribution, and reproduction in any medium, provided the original work is properly cited.

\begin{abstract}
Evidence indicates that root canal preparation is a critical step upon which the prognosis of the endodontic treatment depends. Vertical root fractures can furtherly develop as propagations from the previously formed dentin cracks. Therefore, root canal preparation should be carefully approached with the minimal crack formation and careful dentin removal. Different modalities have been proposed in the literature and rotary systems are most commonly used nowadays. Although the reported efficacy of these modalities is high, evidence shows that they are usually associated with a considerable risk of crack formation. In the present literature review, we have discussed the effects of rotary instrumentation and root canal preparation on dentinal crack formation based on evidence from the different studies in the literature. Our evidence showed that all of the investigated approaches to prepare root canals adequately can result in crack formation. The different rotary instrumentations also showed variable frequencies of developing dentinal cracks, and evidence from some comparative investigations shows that ProTaper modalities are associated with the least frequencies of the events. However, to make a solid conclusion for clinical practice, further research is still needed to validate our current evidence.
\end{abstract}

Keywords: Endodontics, Treatment, Root canal preparation, Dentin cracks, Rotary system

\section{INTRODUCTION}

Evidence indicates that root canal preparation is a critical step upon which the prognosis of the endodontic treatment depends. ${ }^{1}$ The main aim of root canal treatment is to eradicate the underlying debris, microorganisms and residual tissues that reside in the root canal. Besides, this treatment approach is also done to widen the diameter of the canal with adequate apical size and smoothen its walls to successfully achieve 3 dimensional obturation and enhance irrigation. ${ }^{2}$ However, some investigations have reported that some unavoidable negative outcomes are usually associated with the different root canal instrumentation modalities. It has been indicated that 
some craze lines and micro cracks might develop within the dentin walls due to the stress that is generated secondary to the potential contact between the canal wall and the used instrument during the biochemical preparation of the canal before initiating the treatment. ${ }^{2}$

Vertical root fractures can furtherly develop as propagations from the previously formed dentin cracks. ${ }^{3}$ Teeth extraction is attributed to vertical root fractures in $10.9-31 \%$ of the cases. ${ }^{4}$ It has also been demonstrated that there is a correlation between crack formation and the amount of removed dentin and therefore, developing fractures is significantly associated with canal enlargement. ${ }^{2}$ Therefore, root canal preparation should be carefully approached with the minimal crack formation and careful dentin removal. Different modalities have been proposed in the literature and rotary systems are the most commonly used nowadays. ${ }^{5-7}$ Although the reported efficacy of these modalities is high, evidence shows that they are usually associated with a considerable risk of crack formation. Therefore, this literature review aimed to elaborate on the effect of rotary systems and root canal preparation on dentin crack formation.

\section{Methods}

This literature review was based on an extensive literature search in Medline, Cochrane and EMBASE databases which was performed on 15 September 2021 using the medical subject headings (MeSH) or a combination of all possible related terms, according to the database. To avoid missing potential studies, a further manual search for papers was done through Google Scholar while the reference lists of the initially included papers. Papers discussing the effect of rotary systems and root canal preparation on dentin crack formation were screened for useful information. No limitations were posed on date, language, age of participants or publication type.

\section{DISCUSSION}

Recent investigations have concluded significant concerns about whether the development of dentin cracks can lead to the development of complete fractures when using rotary files to achieve root canal preparation. ${ }^{3,8,9}$ According to some previous investigations, there has been evidence indicating the significant association between the development of dentin cracks and the taper and design of the rotary files. The effect of the ProTaper university rotary system was investigated in a previous investigation to find its impact on the development of dentin cracks. Evidence indicated that based on the manufacturer's, evidence indicated that these modalities were first introduced to prepare the apical regions of the canal. It had been demonstrated that the probability of dentin crack formation might be higher when using these files in the process of root canal preparation which was attributable to the design of these files as they had large apical taper finishing files. ${ }^{3}$ As a result, it had been demonstrated that using these modalities was usually associated with increased stress over the dentin walls more than what had been observed with other rotary systems. Furthermore, it had also been demonstrated that the ProTaper systems were usually applied with a single length technique, although crown down manner had been reported with various rotary systems that were currently reported in the literature. ${ }^{10}$ On the other hand, it should be noted that some previous investigations also indicated that when using the crown down rotary instrumentation, increased development of dental cracks was also observed with these modalities. ${ }^{8,9,11}$ Moreover, it had been demonstrated that evidence regarding the formation of dental cracks following the administration of singlelength techniques in root canal preparation was still scarce and needed further demonstration. Mandibular incisors have thin walls and small dimensions and therefore, they were at increased risk to be influenced by the differently applied forced during instrumentation and root canal preparation. Therefore, they represented ideal candidates among the different studies in the literature that investigated the impact of rotary files on the formation of dentin cracks. ${ }^{12}$ It should also be noted that some previous investigations also used mandibular premolars in such events. ${ }^{8,9,11}$ It was also previously hypothesized that if large rotary files cannot influence crack formation in weak incisor teeth during root canal preparation, it would be logical to conclude that these files will not influence the formation of cracks when preparing other teeth.

In a previous investigation by Milani et al it had been demonstrated that using ProTaper systems was not significantly associated with dental crack formation as the authors used two groups, including a control one and the included teeth were matched by size and teeth that had cracks and two canals were excluded from this investigation. ${ }^{12}$ It has been furtherly elaborated that there was a similarity between the taper of roots that were prepared by hand instrumentation and the apical taper of the last finishing rotary file. This indicated the reliability of the reported findings in this investigation because the two groups were similar regarding the taper of the prepared roots, whether when using hand instrumentation or when using rotary files. Such findings were also reported among other similar investigations in the literature. ${ }^{3,11}$ Previous investigations also compared rotary nickel-titanium instruments and air and electric-driven handpieces in settings of rotary canal preparation and concluded that no significant differences were noticed among the two modalities in terms of breakage and restoration of the canal which might induce dentin crack formation. ${ }^{10}$ On the other hand, electric handpieces have more speed and better control of the torque and therefore previous investigations have demonstrated that these modalities can significantly impact the durability of the efficacy of the instruments. ${ }^{13,14}$ Evidence also indicated that it was difficult to assess the rpm levels using airderived handpieces than using electric-derived instruments. Accordingly, it had been suggested that electric-derived instruments should be used with rotary 
files rather than air-derived ones for this reason. On the other hand, evidence also showed an increasing trend for the use of reduced gear, air-driven rotary instruments among different countries, which was probably due to the estimated low costs of these modalities.

It was widely known that the periodontal ligament played an important role in root canal preparation because it can significantly dissipate the stress that was usually applied to the tooth by increased external forces, which was probably due to the viscoelastic properties of the ligament. Accordingly, it had been demonstrated that stimulating the periodontal ligament was an essential approach when investigating the impact of the different instrumentations on strong fractures and cracks formation. ${ }^{15}$ This can be done by using polyether impression materials as proposed by previous investigations in the literature. ${ }^{12,15-17}$ The use of these materials had been attributed to the nonlinear viscoelastic characteristics, which were significantly similar to the naturally occurring properties of the periodontal ligament. ${ }^{18,19}$ However, it should be noted that among some studies in the literature, this suggested approach was not considered when evaluating the impact on dental crack formation. ${ }^{3,8}$ Evidence indicated that the process of dental canal preparation can significantly influence the development of dentin cracks. ${ }^{12}$ This had been indicated in a previous investigation by Shemesh et al that reported that teeth that were used for root canal preparation were more susceptible to fractures and were associated with an increased frequency of crack formation. ${ }^{8}$ It had been furtherly demonstrated that rotary and hand instrumentation modalities had almost equal frequencies of communicating fractures and cracks. It should be noted that the clinical importance was usually directed to the events of dental fractures. However, it was also critical to pay adequate attention to the underlying cracks to enhance the prognosis of the affected teeth. ${ }^{12}$

This was because future dental procedures and other pressure-inducing forces might lead to the propagation of these cracks into developing complete fractures. Previous investigations also showed the dentin cracks that followed dental canal preparation were mainly external and no internal craze lines were reported by these studies. ${ }^{3,8}$ The previous investigation by Shemesh et al indicated this by showing that all the observed cracks were remarkably away from being directly connected with the used instrumentation devices and none of them was in direct contact with the canal space. ${ }^{8}$ This had been explained in the investigation by Wilcox et al that suggested that the pressure applied by the instrumentation device during root canal preparation might be attributable to the transmission of these forces to the outer tooth surface. ${ }^{20}$

Evidence also indicated that hand instrumentation was usually more significantly associated with the development of dentin cracks as compared to the control group. On the other hand, it had been furtherly demonstrated that rotary instrumentation did not significantly differ from the control groups in terms of crack formation. ${ }^{12}$ This indicated that hand instrumentation usually tended to increase the risk of dentin crack formation more than other relevant modalities. On the other hand, a previous investigation by Bier et al demonstrated that the frequency of crack formation was not significantly associated with the use of hand instrumentation devices. ${ }^{3}$ This can be attributed to the fact that among studies that indicated significance, step-back techniques were used, while in studies where the significance was not present, balanced force techniques were used. Accordingly, further research was required to make a final decision about the impact of hand instrumentation on developing dentin cracks and whether they should still be considered in these settings. Previous studies have indicated the association between root canal preparation and the development of dental cracks and without stimulation of the periodontal ligament. ${ }^{3,8,12}$ Current evidence indicated that NiTi files were the most commonly used files to achieve successful root canal preparation. Further investigations also indicated that these files were associated with smoother canal surfaces and rounded shapes when they were used in root canal preparation and therefore, in a previous investigation by Sathorn et al the authors demonstrated that the strength of fracture and frequency of crack formation among these events were more significantly associated than with the cases of using hand technique instrumentations for root canal preparation. ${ }^{21-23}$ Another investigation by Khoshbin et al compared the effect of four different instrumentations on developing dentin cracks during root canal preparation. ${ }^{24}$ The authors demonstrated that all of the used rotary files in this study were associated with developing dentinal cracks and on the other hand, no cracks were observed in the control group. The frequency of developing cracks was $48 \%$, $80 \%, 92 \%$ and $68 \%$ for Neolix, Reciproc, ProTaper and Mtwo rotary files, respectively. Moreover, it had been furtherly demonstrated that the ProTer group was significantly associated with more frequent crack formation Mtwo and Neolix groups and no other significant correlations were found between any of the other study groups. Another investigation was also conducted by Shantiaee et al and compared different modalities that were used to achieve root canal preparation including a control group, hand instrumentation group, ProTaper group, WaveOne group and OneShape rotary file instrumentation. ${ }^{7}$

It had been reported that the development of dentinal cracks was significantly different among these groups. Besides, the authors reported that the OneShape and WaveOne groups had significantly more frequencies in terms of developing dentinal cracks than the control, ProTaper and hand instrumentation groups. Accordingly, it had been concluded that rotary instrumentation, when used for root canal preparation, can result in developing root canal damage, especially in the apical third of the 
root canal. Therefore, it should be noted that further investigations are still needed to elaborate the differences among the current investigations and to adequately interpret the findings for validation of the most appropriate modalities for clinicians and dentists.

\section{CONCLUSION}

In the present literature review, we have discussed the effects of rotary instrumentation and root canal preparation on dentinal crack formation based on evidence from the different studies in the literature. Our evidence shows that all of the investigated approaches to prepare root canals adequately can result in crack formation. The different rotary instrumentations also show variable frequencies of developing dentinal cracks, and evidence from some comparative investigations shows that ProTaper modalities are associated with the least frequencies of the events. However, to make a solid conclusion for clinical practice, further research is still needed to validate our current evidence.

Funding: No funding sources

Conflict of interest: None declared

Ethical approval: Not required

\section{REFERENCES}

1. Peters OA. Current challenges and concepts in the preparation of root canal systems: a review. J Endodont. 2004;30(8):559-67.

2. Yoldas O, Yilmaz S, Atakan G, Kuden C, Kasan Z. Dentinal microcrack formation during root canal preparations by different NiTi rotary instruments and the self-adjusting file. $\mathbf{J}$ Endodont. 2012;38(2):232-5.

3. Bier CA, Shemesh H, Tanomaru-Filho M, Wesselink PR, Wu MK. The ability of different nickel-titanium rotary instruments to induce dentinal damage during canal preparation. J Endodont. 2009;35(2):236-8.

4. Fuss Z, Lustig J, Katz A, Tamse A. An evaluation of endodontically treated vertical root fractured teeth: impact of operative procedures. $\mathrm{J}$ Endodont. 2001;27(1):46-8.

5. Gambill JM, Alder M, Rio CE. Comparison of nickel-titanium and stainless steel hand-file instrumentation using computed tomography. J Endodont. 1996;22(7):369-75.

6. Kim HC, Lee MH, Yum J, Versluis A, Lee CJ, Kim BM. Potential relationship between design of nickeltitanium rotary instruments and vertical root fracture. J Endodont. 2010;36(7):1195-9.

7. Shantiaee Y, Dianat O, Mosayebi G, Namdari M, Tordik P. Effect of root canal preparation techniques on crack formation in root dentin. $\mathrm{J}$ Endodont. 2019;45(4):447-52.

8. Shemesh H, Bier CA, Wu MK, Tanomaru-Filho M, Wesselink PR. The effects of canal preparation and filling on the incidence of dentinal defects. Int Endodont J. 2009;42(3):208-13.

9. Adorno CG, Yoshioka T, Suda H. Crack initiation on the apical root surface caused by three different nickel-titanium rotary files at different working lengths. J Endodont. 2011;37(4):522-5.

10. Bortnick KL, Steiman HR, Ruskin A. Comparison of nickel-titanium file distortion using electric and air-driven handpieces. J Endodont. 2001;27(1):57-9.

11. Adorno CG, Yoshioka T, Suda H. The effect of working length and root canal preparation technique on crack development in the apical root canal wall. Int Endodont J. 2010;43(4):321-7.

12. Milani AS, Froughreyhani M, Rahimi S, Jafarabadi MA, Paksefat S. The effect of root canal preparation on the development of dentin cracks. Iran Endod J. 2012;7(4):177-82.

13. Daugherty DW, Gound TG, Comer TL. Comparison of fracture rate, deformation rate, and efficiency between rotary endodontic instruments driven at 150 rpm and 350 rpm. J Endodont. 2001;27(2):93-5.

14. Gabel WP, Hoen M, Steiman HR, Pink FE, Dietz R. Effect of rotational speed on nickel-titanium file distortion. J Endodont. 1999;25(11):752-4.

15. Bortoluzzi EA, Souza EM, Reis JM, Esberard RM, Tanomaru-Filho M. Fracture strength of bovine incisors after intra-radicular treatment with MTA in an experimental immature tooth model. Int Endodont J. 2007;40(9):684-91.

16. Soares CJ, Martins LR, Pfeifer JM, Giannini M. Fracture resistance of teeth restored with indirectcomposite and ceramic inlay systems. Quintess Int. 2004;35(4):281-6.

17. Rosentritt M, Fürer C, Behr M, Lang R, Handel G. Comparison of in vitro fracture strength of metallic and tooth-coloured posts and cores. J Oral Rehabilit. 2000;27(7):595-601.

18. Jamani KD, Harrington E, Wilson HJ. Rigidity of elastomeric impression materials. J Oral Rehabilit. 1989;16(3):241-8.

19. Yoshida N, Koga Y, Peng CL, Tanaka E, Kobayashi $\mathrm{K}$. In vivo measurement of the elastic modulus of the human periodontal ligament. Med Eng Phys. 2001;23(8):567-72.

20. Wilcox LR, Roskelley C, Sutton T. The relationship of root canal enlargement to finger-spreader induced vertical root fracture. J Endodont. 1997;23(8):533-4.

21. Sathorn C, Palamara JE, Messer HH. A comparison of the effects of two canal preparation techniques on root fracture susceptibility and fracture pattern. J Endodont. 2005;31(4):283-7.

22. Thompson SA, Dummer PM. Shaping ability of ProFile.04 Taper Series 29 rotary nickel-titanium instruments in simulated root canals. Part 1. Int Endodont J. 1997;30(1):1-7.

23. Bryant ST, Thompson SA, Omari MA, Dummer PM. Shaping ability of profile rotary nickel-titanium instruments with ISO sized tips in simulated root canals: part 1. Int Endodont J. 1998;31(4):275-81. 
24. Khoshbin E, Donyavi Z, Atibeh EA, Roshanaei G, Amani F. The effect of canal preparation with four different rotary systems on formation of dentinal cracks: an in vitro evaluation. Iran Endod J. 2018;13(2):163-8.
Cite this article as: Abulhamayel AA, Altukhays HA, Alamri HA, Salem AA, Farrash JA, Alshammari AZ, et al. Effect of rotary systems and root canal preparation and dentin crack formation. Int $\mathbf{J}$ Community Med Public Health 2021;8:5578-82. 